\title{
Probe distractors can influence negative priming by perceptual grouping
}

\author{
YEI-YU YEH and HSUAN-FU CHAO \\ National Taiwan University, Taipei, Taiwan
}

\begin{abstract}
Negative priming occurs when a response is slower to a target that was a previously ignored stimulus. According to a computational model of inhibition, negative priming results from relative activation between a target and a distractor in probe trials. Thus, the degree of competition in the probe trial should influence negative priming. The results from three experiments supported this hypothesis. Probe distractors grouped with a target by a rectangle produced a larger negative priming effect than did distractors isolated from the target. Moreover, neither prime-probe similarity nor perceptual interference could explain the grouping effect. The results suggest that perceptual mechanisms can influence negative priming via a race in the probe trial.
\end{abstract}

As a person perceives and responds to task-relevant stimuli, distractors act on attention as decoys. Focused attention is required to correctly integrate task-relevant features (Treisman \& Gelade, 1980). Without it, a person can easily misidentify a stranger in a crowd who looks like a friend. Focused attention is also required to prevent slips in action (Tipper, Meegan, \& Howard, 2002). Without it, a person can easily press the wrong buttons in making a phone call. When attention is focused on stimuli relevant to behavioral goals, inhibitionis a viable strategy by which selection mechanisms may reduce distractors' interference.

However, inhibition is not without a cost. The cost surfaces when a decoy becomes the target, as the paradigm of negative priming demonstrates. Negative priming requires the use of pairs of consecutive prime and probe trials. Participants are asked to respond to a target item while ignoring other, distracting items. When the distractor item from the prime trial becomes the target item in the subsequent probe trial (the ignored repetition [IR] condition), participants' responses are slower or less accurate, in comparison with their responses in conditions in which prime and probe trials share no items (the control condition). This delay in response is a demonstration of the negative priming effect, the cost of selective attention in information processing. If the priming effect is a measure of change in the activation state of item representation (see Milliken,

Parts of this work were presented in April 2002 at the 5th Conference on Attention and Perception in Chia-Yi, Taiwan, R.O.C. We thank the Ministry of Education Committee for the Promotion and Propagation of the National Language for providing the database from which we selected the stimuli. We also thank Dr. Fuentes, Dr. Mari-Beffa, and Dr. Neill for their critical comments. Correspondence concerning this article should be addressed to Y.-Y. Yeh, Department of Psychology, National Taiwan University, No. 1, Sec. 4, Roosevelt Rd., Taipei, Taiwan 106 R.O.C. (e-mail: yyy@ntu.edu.tw).

Note-This article was accepted by the previous editorial team, headed by Neil Macmillan.
Lupiáñez, Debner, \& Abello, 1999, for a discussion on what negative priming can reflect), negative priming can be considered to reflect the inhibitory component of selective attention (Neill, 1977; Tipper, 1985; Tipper \& Cranston, 1985).

Because everyday cognition involves information selection, inhibition should operate universally across different $\operatorname{cognitive}$ tasks. The evidence indeed has supported the universal nature of inhibition in cognition (see Dagenbach \& Carr, 1994) and also the occurrence of the negative priming effect across a variety of tasks, including naming (Neill, 1977), location judgment (Tipper, Brehaut, \& Driver, 1990), lexical decision (Yee, 1991), categorization (Chiappe \& MacLeod, 1995; Tipper \& Driver, 1988), perceptual matching (DeSchepper \& Treisman, 1996), and size judgment (MacDonald, Joordens, \& Seergobin, 1999). Negative priming has also been observed with a variety of stimulus materials: simple symbols (Tipper et al., 1990), letters (Tipper \& Cranston, 1985), objects (Tipper, 1985; Tipper \& Driver, 1988), words (Malley \& Strayer, 1995), colored words (Neill, 1977), and nonsense shapes (DeSchepper \& Treisman, 1996).

To operate effectively in various contexts, the human information-processing system should conserve cognitive resources and initiate inhibition in the prime trial only when distractors compete for selection, because ubiquitous as it is, inhibition itself demands cognitive resources (Conway, Tuholski, Shisler, \& Engle, 1999; Engle, Conway, Tuholski, \& Shisler, 1995). At times, through the lengthening of the interval between the prime and the probe trials, a task may require maintenance of inhibition over a long period, such as 2,500 msec (Hasher, Zacks, Stoltzfus, Kane, \& Connelly, 1996) or 6,600 msec (Tipper, Weaver, Cameron, Brehaut, \& Bastedo, 1991). Evidence has emerged to support the view that inhibition is sensitive to the activation of prime distractors (Houghton \& Tipper, 1994) and that it operates when irrelevant information in the prime display arouses strong competition 
(Malley \& Strayer, 1995; Strayer \& Grison, 1999; but see Neill \& Joordens, 2002, for a rebuttal). Negative priming thus reflects the operation of a protecting mechanism (Moore, 1994; Tipper \& Cranston, 1985) that reacts to selection difficulty.

Protection is at work when prime distractors are in close proximity to the target. To demonstrate negative priming, researchers often use overlapping stimuli, with a distractor superimposed on a target (e.g., Neumann \& DeSchepper, 1991; Tipper 1985), or use a flanker display (e.g., Fox, 1994; Fuentes, Humphreys, Agis, Carmona, \& Catena, 1998) in which distractors are positioned beside the target. Moreover, Fox (1994) observed the negative priming effect only when prime distractors were near $\left(0.97^{\circ}\right)$ or at a medium distance from $\left(1.7^{\circ}\right)$ the target and observed no effect when distractors were far from $\left(2.6^{\circ}\right)$ the prime target. That is, only prime distractors close to the target can impose strong competition and elicit inhibition when the distance between the target and the distractors is manipulated.

Prime distractors in a state of high activation also impose strong competition and influence negative priming. Assuming that repetition increases activation, Strayer and his colleagues (Malley \& Strayer, 1995; Strayer \& Grison, 1999) manipulated the level of competition by using either repeated or nonrepeated stimuli as prime distractors. They found negative priming only when the prime distractors were repeated stimuli, and not when the distractors were nonrepeated stimuli (see Neill \& Joordens, 2002, and Strayer, Drews, \& Albert, 2002, for discussions of the impact of stimulus repetition on negative priming). Furthermore, the contingency of negative priming on stimulus repetition was universal across age groups between college students and elderly participants (Kramer \& Strayer, 2001).

With evidence converging to support the fact that strongly competitive prime distractors elicit the inhibitory element of selective attention, less effort has been devoted to understanding how the characteristics of probe distractors can influence negative priming. Yet results have shown that negative priming depends on the presence of probe distractors (Lowe, 1979; Tipper \& Cranston, 1985). The presence of probe distractors may serve multiple functions. One is to provide prime-probe similarity, given that distractors are usually present in the study of negative priming (but see Milliken, Joordens, Merikle, \& Seiffert, 1998 , on the lack of necessity for prime distractors). According to the memory retrieval view (Neill \& Mathis, 1998; Neil, Terry, \& Valdes, 1994; Neill \& Valdes, 1992; Neill, Valdes, Terry, \& Gorfein, 1992), negative priming results from a retrieval of inappropriate information from previous episodes. When a person processes a target that was a distractor in a recent episode, retrieval of incompatible memory traces, such as the response tag "do not respond to it," interferes with the correct response. It takes time to resolve the conflict in response selection, resulting in the negative priming effect. Because perceptual similarity can influence the retrieval process by the encoding specificity principle (Tulving \& Thomson, 1973), simi- larity in the prime-probe couplets through the presence of probe distractors can influence negative priming.

Another function of the probe distractor is to impose competition with the probe target in the selection process, the same role as that played by the prime distractors. The objective of this study was to verify how the degree of competitionimposed by probe distractors would influence negative priming. Houghton and Tipper (1994) in their computation model suggested this role of probe distractors to account for the dependency of negative priming on probe distractors. Response, in this model, depends on a race between the probe target and the probe distractor. For a correct response to be made, the activation level of the target must be sufficiently higher than that of the distractor. In comparison with the control condition, the internal representation of a prime distractor is inhibited in the IR condition, and thus the initial activation level of this item at probe onset as a target is below the resting baseline level. In contrast, the activation level of a probe distractor is at the resting level at probe onset. Because the activation level of the probe target is lower than that of the probe distractor, it takes longer for the processing system to accumulate the target's activation level enough to surpass that of the distractor. Negative priming results. When the distractor is absent in the probe trial, response to an inhibited target can still be output quickly, because it has no competitor in the race. Behavioral measures cannot detect the cost of inhibition when probe distractors are absent. Thus, negative priming is manifested only when there are probe distractors in the race.

Although the inhibition account explicates how race in the probe trial can influence negative priming, the memory retrieval account (Neill, 1997; Neill \& Mathis, 1998; Neill et al., 1992) implicates the role of probe competition. According to Neill's theory, the relative speeds for the algorithmic computation and the memory retrieval of a target determine task performance. Negative priming is manifested when memory retrieval prevails. Strong competition in the probe trial can lengthen algorithmic computation for memory retrieval of the inappropriate response information, producing negative priming. Thus, competition in the probe trial should also influence negative priming.

Because the level of competitionimposed by probe distractors influences the amount of activation that the processing system must accumulate in the target representation to win the race in the inhibition account and to delay algorithmic computation in the retrieval account, it should affect target selection and, hence, negative priming (Chao, 2001). That is, strongly competitive probe distractors should produce a larger negative priming effect than do weakly competitive distractors. Empirical evidence testifying to the hypothesis, however, is equivocal.

Manipulating the degree of stimulus repetition, Chao (2001) demonstrated that the level of competition imposed by probe distractors could influence negative priming in certain contexts. For example, when the manipulation of configurative similarity was not salient enough to 
trigger memory retrieval (e.g., maintaining the same linear layout or rotating the layout $90^{\circ}$ ), distractor competition in the probe trial influenced negative priming. Probe distractors from a small set of stimuli that were repeated throughout the experimental session produced a larger negative priming effect than did distractors from a large set of stimuli that did not occur until the prime trial. Yet Moore (1994) and Milliken et al. (1999) showed that the degree of competition was not crucial in negative priming. Negative priming could be manifested when probe trials did not contain conflicting information.

Studies in which the interaction between activation and inhibition in negative priming (Lowe, 1979; Neumann \& DeSchepper, 1991; Stadler \& Hogan, 1996) also has been investigated have shown mixed results with respect to the prediction of the competition hypothesis. In these studies, researchers manipulated the level of activation in the probe target and distractors by using stimuli that had been prime targets, were neutral letters, or had been prime distractors, with the assumption that the level of activation would decrease accordingly. Inconsistency could be shown in a comparison of the results of two conditions in which probe targets were the prime distractors while probe distractors were either neutral (e.g., $\mathrm{c} \mathrm{b} \mathrm{c} \rightarrow \mathrm{n} \mathrm{c} \mathrm{n}$ ) or prime targets (e.g., c b c $\rightarrow$ b c b). Internal representations of probe distractors in the latter condition should be at a higher level of activation, because of recent excitation. Given that target activation was identical in these two conditions, negative priming should be larger in the latter condition than in the former, if distractor competition in the probe trial was important. Although two studies (Neumann \& DeSchepper, 1991; Stadler \& Hogan, 1996) showed the predicted pattern, one study (Lowe, 1979) showed a reverse pattern. Because of differences in methodology, it is difficult to account for the inconsistency.

Since the role of competitors in probe distractors is as yet undetermined, we examine how probe distractors may influence negative priming through perceptual grouping with the target. The hypothesis is that distractors grouped with a target impose greater competition than do distractors that are not grouped with the target. If the degree of competition influences the race at probe onset, distractors grouped with the target should result in a larger negative priming effect.

Perceptual grouping is a way to control the unit on which selective attention focuses. Visual attention can be object based (Baylis \& Driver, 1992; Duncan, 1984), and selective attention to visual attributes in a single object is more efficient than attention to the same attributes in two objects (e.g., Duncan \& Nimmo-Smith, 1996; Lappin, 1967). Stimulus identification of a word and detection of a gap in an outline box is better when they form a perceptual unit (Treisman, Kahneman, \& Burkell, 1983). Information from different feature dimensions can be processed in parallel if they belong to the same object (Allport, 1971; Wheeler \& Treisman, 2002; Wing \& Allport, 1972; Xu, 2002). Furthermore, perceptual grouping by common fate, such as color (Baylis \& Driver, 1992) or motion (Driver \& Baylis, 1989), can influence selective attention. Grouping of display elements by symmetry, closure, or both also influences selection (Donnelly, Humphreys, \& Riddoch, 1991; Pomerantz, 1981).

Because visual attention spreads across the entire spatial extent of objects (Davis, Driver, Pavani, \& Shepherd, 2000), all elements in the same group are processed together (Duncan, 1995). Because all elements in the same group are processed together and receive activation, distractors grouped with a target in the same perceptual group should impose greater competition than do distractors that are not grouped with the target. Perceptual grouping thus should influence negative priming. Fox (1998) demonstrated the influence of perceptual grouping in the prime display on negative priming. She found that distant distractors in a prime display that shared the same color as the target could induce negative priming, whereas near distractors with a different color did not produce negative priming. Distant distractors connected to targets by horizontal lines in the prime display as a perceptual group also produced negative priming, whereas distant distractors isolated from the target produced a marginally positive priming effect in the IR condition.

However, Fuentes et al. (1998) showed that distractors grouped with a prime target could facilitate processing when they became probe targets. Similar to Fox's (1998) study, they used a flanker display (Eriksen \& Eriksen, 1974) with two identical distractors positioned next to a target. They showed positive priming when two flanking distractors were grouped with the prime target in a rectangle. Although the two studies on negative priming had contradictory findings on the influence of perceptual grouping in the prime display, the results showed that distractors are activated along with the target when they are grouped in the same unit. The difference lies in the subsequent fate: Prime distractors remained activated in the study of Fuentes et al. (1998) and were inhibited in Fox's (1998) study. Task requirements may have caused the difference in findings (Fuentes et al., 1998). We assumed that probe distractors should also be activated, along with a target, when they were grouped with the target as a larger unit. We expected to find larger negative priming in this condition, because of the stronger competition imposed by probe distractors, which would delay the target from winning the race at probe onset. The results from the three experiments of this study supported this prediction.

\section{EXPERIMENT 1}

The presentation used a flanker display with a rectangle in the probe display to manipulate perceptual grouping. Rather than asking the participants to match the targets across prime and probe trials, as Fuentes et al. (1998) did, we used a naming task such that the participants did not need to remember the prime target while processing the probe display. A target and its two distractors in the probe trial were either grouped together within a rectangle (highcompetition condition) or not (low-competition condi- 
tion), whereas targets and distractors of prime trials were always grouped together by a rectangle (see Figure 1). We predicted larger negative priming in the former than in the latter condition.

\section{Method}

Participants. Twenty undergraduate students at National Taiwan University participated in this experiment for a bonus credit in an introductory psychology course. All the participants were naive as to the purpose of the experiment and had normal or corrected-to-normal vision.

Design and Stimuli. A 2 (couplet type: IR/control) $\times 2$ (level of competition: high/low) factorial design was used. There were 16 prime-probe couplets in each of the four conditions, producing 64 prime-probe couplets in the experiment. Each couplet consisted of a prime trial and a subsequent probe trial. In the control condition, the prime trials and the probe trials shared no items. In the IR condition, a prime distractor became the probe target of the same couplet. Negative priming was measured by contrasting performance in the IR condition with that in the control condition.

Eight Chinese character words of high count frequency, ranging from 1,765 to 2,017 per million (Ministry of Education, 1997) and with the number of strokes ranging from five to eight were used as stimuli. Each word was repeated with equal frequency as a prime target, a prime distractor, a probe target, and a probe distractor throughout the experiment. Inhibition should operate in this context because prime distractors of high activation from repetition impose strong competition (Malley \& Strayer, 1995; Strayer \& Grison, 1999). Our interest, however, was the influence of perceptual grouping in probe displays on negative priming - that is, the interaction between the two variables in the design.
The target was presented on the screen center, with another word flanking it on both the left and the right sides. The participants viewed the stimuli at a distance of approximately $60 \mathrm{~cm}$. At the viewing distance, each word subtended a visual angle of $0.86^{\circ}$ vertically and $0.86^{\circ}$ horizontally. The center-to-center distance from the target to a distractor was $2.48^{\circ}$ of visual angle. All the stimuli were presented in white on a black background. The rectangle surrounding a target and two distractors was also presented in white. It was positioned so that the stimulus display was in the center of the rectangle. The rectangle had a width of $7.78^{\circ}$, a height of $1.43^{\circ}$, and a border thickness of $0.19^{\circ}$.

Procedure. The experiment was run by DMDX software (Forster $\&$ Forster, 2003). Naming latency was measured with a microphone connected to an audio card, and the experimenter recorded naming accuracy. Each participant was tested individually.

The participants were instructed to name the center target as quickly and as accurately as possible. They were also told to ignore the two words adjacent to the target, because the distractors could interfere with their responses. To provide a rationale for the presence of a rectangle, the participants were further told that this rectangle was there to assist them to localize the target. Eight practice trials were conducted to familiarize the participants with the experimental procedure. All the prime-probe couplets were then run in a random sequence, with a rest period halfway through the experiment.

The time course of a prime-probe couplet was as follows. A cross on screen center and a "ding" sound were simultaneously presented for $300 \mathrm{msec}$ as a warning signal. A stimulus display was subsequently presented on the screen until the participant spoke the word or until $3 \mathrm{sec}$ had elapsed. The next warning display was presented with a delay of $200 \mathrm{msec}$ after the participant had said the word. There were no procedural differences between the prime trials and the probe trials in order to eliminate any observable distinction between the prime trial and the probe trial as a couplet.

Level of Competition from Probe Distractors

High Low

Experiment 1

Primes

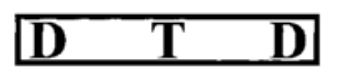

\begin{tabular}{|lll|}
\hline $\mathbf{D}$ & $\mathbf{T}$ & $\mathbf{D}$ \\
\hline
\end{tabular}

Probes

\begin{tabular}{|lll|}
\hline $\mathbf{D}$ & $\mathbf{T}$ & $\mathbf{D}$ \\
\hline
\end{tabular}

D $\quad \mathbf{T} \quad \mathbf{D}$

Experiment 2

Primes

D T D

D T D

Probes

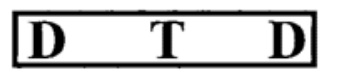

D $\mathbf{T}$

D

Experiment 3

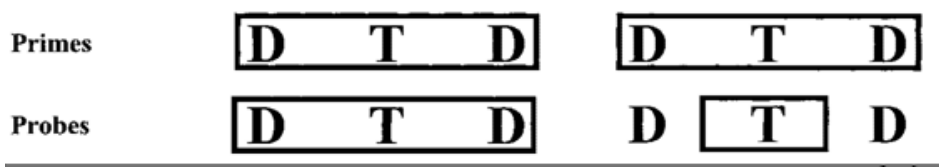

Figure 1. Illustrations of the manipulations of competition from probe distractors by grouping in Experiments 1, 2, and 3. T, target; D, distractor. 
Table 1

Averaged Median Correct Reaction Times (in Milliseconds) and Accuracy

(\%) of Two Couplet Types and Effects of Negative Priming (NP)

at Different Levels of Probe Distractor Competition in Experiment 1

\begin{tabular}{|c|c|c|c|c|c|c|c|c|c|}
\hline \multirow[b]{4}{*}{ Competition } & \multicolumn{8}{|c|}{ Couplet Type } & \multirow[b]{4}{*}{ NP } \\
\hline & \multicolumn{4}{|c|}{ IR } & \multicolumn{4}{|c|}{ Control } & \\
\hline & \multicolumn{2}{|c|}{ RT } & \multicolumn{2}{|c|}{ Accuracy } & \multicolumn{2}{|c|}{ RT } & \multicolumn{2}{|c|}{ Accuracy } & \\
\hline & $M$ & $\overline{S D}$ & $M$ & $\overline{S D}$ & $M$ & $S D$ & $M$ & $S D$ & \\
\hline High & 505.6 & 46.0 & 98.3 & 2.9 & 491.4 & 47.5 & 99.4 & 1.9 & -14.1 \\
\hline Low & 492.2 & 40.7 & 100.0 & 0.0 & 492.5 & 43.2 & 99.4 & 1.9 & 0.3 \\
\hline
\end{tabular}

Note-IR, ignored repetition. NP is calculated as the difference between the IR condition and the control condition.

\section{Results}

A total of $4.21 \%$ of the trials were excluded from data analysis because of recording failures (e.g., the voice was not registered or the participant coughed) or errors in responding to the prime display. Thus, both reaction time (RT) and accuracy reflected the performance in correctly naming probe targets contingent upon correct response to the prior prime targets. The average median RT and accuracy for each condition are presented in Table 1.

Median RTs were analyzed with a repeated measures analysis of variance (ANOVA). This analysis showed that the main effects both of couplet type $[F(1,19)=3.49$, $\left.M S_{\mathrm{e}}=277.02, p=.074\right]$ and of level of competition $\left[F(1,19)=4.16, M S_{\mathrm{e}}=180.48, p=.053\right]$ were marginally significant. More important, the interaction between these two factors was significant $\left[F(1,19)=4.32, M S_{\mathrm{e}}=\right.$ 243.61, $p<.05]$. An analysis of simple main effects showed that the effect of couplet type was significant when the level of competition was high $[F(1,38)=7.75$, $\left.M S_{\mathrm{e}}=260.31, p<.01\right]$, but not when the level of competition was low $[F(1,38)=0.003, p>.15]$. This interaction revealed that negative priming manifested only when competition from the probe distractors was high.

Accuracy data were also analyzed with a repeated measures ANOVA. The main effect of level of competition was marginally significant $\left[F(1,19)=3.07, M S_{\mathrm{e}}=4.58\right.$, $p=.093]$. The interaction of couplet type and level of competition was also marginally significant $[F(1,19)=$ $3.27, M S_{\mathrm{e}}=4.29, p=.083$ ], showing negative priming in accuracy when competition from the probe distractors was high.

\section{Discussion}

The results of this experiment showed that negative priming was observed only when the distractors were grouped with the target in the probe display. This finding supports the competition hypothesis - that is, the competition imposed by the probe distractors is critical to the manifestation of negative priming. When a rectangle was present, the distractors were activated at probe onset and inflicted strong competition against the target in the selection process race. When the rectangle was absent, visual attention could focus on the target more effectively. The probe distractors imposed less competition, and their in- ternal representation received less activation. An inhibited target could still be output quickly, and the cost of inhibition was not observed, in this low competition condition.

The results, however, may have reflected the effect of prime-probe similarity, rather than indicating the influence of distractor competition. Empirical evidence has shown that the magnitude of the negative priming effect is influenced by the similarity between the prime and the probe trials, with larger negative priming when the prime and the probe trials share similar characteristics, such as display luminance contrast (Fox \& de Fockert, 1998; Stolz \& Neely, 2001), stimulus onset asynchrony between a target and a distractor (Neill, 1997; but see Moore, 1996, for different results), target-distractor distance and response compatibility (Neill \& Valdes, 1996), or configurative layout (Chao \& Yeh, 2002; but see Wong, 2000, for different results). By presenting a rectangle in the prime display and manipulating grouping in the probe display with the presence of a rectangle, we also varied the prime-probe similarity.

In the high-competition condition, in which a rectangle is present in both the prime and the probe displays, prime trials and probe trials are similar in both perceptual configuration and the level of competition. In the lowcompetition condition, in which a rectangle is present only in the prime display, prime trials and probe trials are dissimilar in perceptual configuration and the level of competition. According to the memory retrieval view, perceptual similarity can influence the retrievability of the prime trial and, hence, the magnitude of negative priming. Thus, the results of Experiment 1 could have resulted from easy retrieval in the high-competition condition, rather than reflecting distractor competition. To examine this alternative explanation, we conducted Experiment 2.

\section{EXPERIMENT 2}

Experiment 2 was designed to test whether the larger negative priming effect in the high-competition condition of Experiment 1 resulted from prime-probe similarity in perceptual configuration or level of distractor competition. The design of this experiment was identical to that of Experiment 1, with only one exception. To increase competition from prime distractors (Malley \& Strayer, 1995; 
Table 2

Averaged Median Correct Reaction Times (in Milliseconds) and Accuracy (\%) of Two Couplet Types and Effects of Negative Priming (NP) at Different Levels of Probe Distractor Competition in Experiment 2

\begin{tabular}{|c|c|c|c|c|c|c|c|c|c|}
\hline \multirow[b]{4}{*}{ Competition } & \multicolumn{8}{|c|}{ Couplet Type } & \multirow[b]{4}{*}{ NP } \\
\hline & \multicolumn{4}{|c|}{ IR } & \multicolumn{4}{|c|}{ Control } & \\
\hline & \multicolumn{2}{|c|}{$\mathrm{RT}$} & \multicolumn{2}{|c|}{ Accuracy } & \multicolumn{2}{|c|}{ RT } & \multicolumn{2}{|c|}{ Accuracy } & \\
\hline & $M$ & $S D$ & $M$ & $S D$ & $M$ & $S D$ & $M$ & $S D$ & \\
\hline High & 517.0 & 64.3 & 98.1 & 3.5 & 502.0 & 62.0 & 99.3 & 2.9 & -15.0 \\
\hline Low & 493.0 & 60.0 & 97.7 & 3.1 & 497.9 & 58.7 & 99.7 & 1.4 & 4.9 \\
\hline
\end{tabular}

Note-IR, ignored repetition. NP is calculated as the difference between the IR condition and the control condition.

Strayer \& Grison, 1999), the distance of prime distractors to prime target was reduced (see Figure 1 for an illustration). ${ }^{1}$ Given that a rectangle was present in the probe display of the high-competition condition, whereas no rectangle grouped probe stimuli in the low-competition condition, perceptual similarity should be higher in the latter condition than in the former condition. ${ }^{2}$

According to the inhibition account, negative priming should be larger when the competition from probe distractors is high, despite the lower similarity in a primeprobe couplet. Whether the memory retrieval account predicts the same result depends on the relative strength between the effect of competition in algorithmic computation and the impact of contextual similarity on memory retrieval. In the high-competition condition, both algorithmic computation and memory retrieval should be delayed. Computation in target analysis is lengthened because probe distractors impose strong competition; memory retrieval is delayed because perceptual similarity is relatively low. If the delay in computation is longer than the delay in retrieval, negative priming should manifest, because memory retrieval can complete the process before computation. In contrast, episodic retrieval in the low-competition condition should be faster than algorithmic computation, because stimulus familiarity from repetition and high word frequency and also relatively higher perceptual similarity should encourage memory retrieval. Negative priming should manifest.

\section{Method}

Participants. Twenty undergraduate students at National Taiwan University participated in this experiment for a bonus credit in an introductory psychology course. All the participants were naive as to the purpose of the experiment and had normal or corrected-to-normal vision.

Design, Stimuli, and Procedure. With the exception that the center-to-center distance from the target to a distractor in prime trials was reduced to $1.15^{\circ}$ in visual angle, all other aspects were identical to those in Experiment 1.

\section{Results}

A total of $3.67 \%$ of the trials were excluded from data analysis because of recording failures (e.g., the voice was not registered, or the participant coughed) or errors in responding to the prime display. Table 2 shows the average median RT and accuracy for each condition.
Median RTs were analyzed with a repeated measures ANOVA. This analysis showed a significant main effect of level of competition $\left[F(1,19)=15.56, M S_{\mathrm{e}}=253.32, p<\right.$ .01]. More important, the interaction between couplet type and level of competition was significant $[F(1,19)=8.45$, $\left.M S_{\mathrm{e}}=233.66, p<.01\right]$. An analysis of simple main effects showed that the effect of couplet type was significant when the level of competition was high $[F(1,38)=$ 9.04, $\left.M S_{\mathrm{e}}=250.67, p<.01\right]$, but not when the level of competition was low $[F(1,38)=0.929, p>.15]$. This interaction revealed that negative priming manifested only when competition from probe distractors was high.

Accuracy data were also analyzed with a repeated measures ANOVA. The main effect of couplet type was significant $\left[F(1,19)=18.79, M S_{\mathrm{e}}=2.75, p<.01\right]$, indicating lower accuracy in the IR condition. Other effects were not significant $(p>.15)$.

\section{Discussion}

This experiment replicated the findings of Experiment 1. Significant negative priming was observed when competition from probe distractors was high, but not when prime displays and probe displays were similar to each other. Thus, the level of competition imposed by the probe distractors, not the prime-probe similarity, influenced negative priming in the present experimental context. Yet the accuracy data showed more errors in the IR condition, whether competition from probe distractors was high or low. This negative priming effect in accuracy is interesting and deserves further study.

\section{EXPERIMENT 3}

Perceptual grouping was used in Experiments 1 and 2 to manipulate competition from probe distractors. Because the high level of competition always entailed the presence of a rectangle, the effects might have resulted from perceptual interference introduced by the rectangle, rather than reflecting the effect of competition from probe distractors. With perceptual interference, target identification may have been impaired. Kane, May, Hasher, Rahhal, and Stoltzfus (1997) have suggested that when target identification is impaired, prior context becomes useful, and memory retrieval is induced to produce negative priming. Thus, it is plausible that negative priming was in- 
Table 3

Averaged Median Correct Reaction Times (in Milliseconds) and Accuracy (\% ) of Two Couplet Types and Effects of Negative Priming (NP) at Different Levels of Probe Distractor Competition in Experiment 3

\begin{tabular}{|c|c|c|c|c|c|c|c|c|c|}
\hline \multirow[b]{4}{*}{ Competition } & \multicolumn{8}{|c|}{ Couplet Type } & \multirow[b]{4}{*}{ NP } \\
\hline & \multicolumn{4}{|c|}{ IR } & \multicolumn{4}{|c|}{ Control } & \\
\hline & \multicolumn{2}{|c|}{ RT } & \multicolumn{2}{|c|}{ Accuracy } & \multicolumn{2}{|c|}{ RT } & \multicolumn{2}{|c|}{ Accuracy } & \\
\hline & $M$ & $S D$ & $M$ & $S D$ & $M$ & $S D$ & $M$ & $S D$ & \\
\hline High & 518.5 & 52.8 & 99.4 & 1.9 & 505.0 & 42.5 & 99.3 & 2.1 & -13.5 \\
\hline Low & 504.8 & 38.4 & 99.4 & 1.9 & 506.5 & 42.3 & 100.0 & 0.0 & 1.7 \\
\hline
\end{tabular}

Note-IR, ignored repetition. NP is calculated as the difference between the IR condition and the control condition.

duced by memory retrieval, and not by the level of competition imposed by probe distractors.

To examine this possibility, Experiment 1 was replicated, but a small rectangle was placed around the probe target in the low-competition condition (see Figure 1). With this design, the influence of competition level was decoupled from the effect induced by the presence of a rectangle. In the low-competition condition, perceptual interference on probe targets was equivalent to or larger than that in the high competition condition, because the left and right borders were adjacent to the targets. If negative priming in the high-competition condition of Experiments 1 and 2 resulted from perceptual interference, equivalent or larger negative priming than that in the highcompetition condition should occur. On the other hand, competition from distractors should be less than that in the high-competition condition, because the small rectangle did not group distractors with their target. If competition from probe distractors is important, a larger negative priming effect in the high-competition condition should occur, because distractors were grouped with the target.

\section{Method}

Participants. Twenty undergraduate students at National Taiwan University participated in this experiment for a bonus credit in an introductory psychology course. All the participants were naive as to the purpose of the experiment and had normal or corrected-to-normal vision.

Design, Stimuli, and Procedure. The method in this experiment was identical to that in Experiment 1, except for the use of a small rectangle surrounding the target in the low-competition condition.

\section{Results}

A total of $4.22 \%$ of the trials were excluded from data analysis. Table 3 presents the average median RT and accuracy for each condition. Median RTs were analyzed with a repeated measures ANOVA. The effect of couplet type significantly interacted with the effect of level of competition $\left[F(1,19)=4.57, M S_{\mathrm{e}}=254.46, p<.05\right]$. An analysis of simple main effects revealed that the effect of couplet type was significant when the level of competition was high $\left[F(1,38)=6.22, M S_{\mathrm{e}}=292.13, p<.05\right]$, but not when the level of competition was low $[F(1,38)=$ $0.11, p>.15]$. The other two main effects were not significant $(p s>.10)$. Accuracy data were also analyzed with an ANOVA, and the results showed no significant effects $(p s>.10)$.

\section{Discussion}

Although a small rectangle placed near the target in the low-competition condition imposed perceptual interference that was equivalent to or larger than a large rectangle in the high-competition condition, the results replicated the pattern of Experiments 1 and 2. That is, there was significant negative priming when the probe distractors were grouped with the target, but not when the probe distractors were isolated from the target. Thus, the probe distractor competition effect should be attributed to the competition from probe distractors, not merely to the perceptual interference from the rectangle.

\section{GENERAL DISCUSSION}

The results of three experiments supported the hypothesis that competition imposed by probe distractors can influence negative priming. Because selective attention guided by perceptual grouping processes all elements in the group, distractors of the same group receive more activation at probe onset than do distractors of a different group. As a result, those of the same group impose stronger competition in the race at probe onset than do distractors of a different perceptual group. Distractors of the same group further delay the race with target selection and produce greater negative priming. The results from the three experiments support this prediction and showed significant negative priming when probe distractors were grouped with a target in the same unit. No priming occurred when probe distractors were not grouped with targets.

Moreover, perceptual similarity in display configuration cannot account for this finding, because the results of Experiment 2 showed that there was significant negative priming when the competition imposed by the probe distractors was high, but not when prime-probe trial was similar (competition from the probe distractors was low). Neither can perceptual interference explain the finding, because the results of Experiment 3 failed to show negative priming when the probe targets were surrounded by a small rectangle and the distractors were not grouped with targets. Perceptual grouping by a rectangle indeed modu- 
lates the degree of competition imposed by distractors via altering the degree of activation that the distractors receive.

The impact of distractors on selection process, however, is intricate. Perceptual grouping did not influence performance on the probe trials in the control condition of any of the three experiments. The influence of distractor competition manifested only in the IR condition, in which the target was a recently inhibited distractor. One possible reason for the null results in the control condition was our use of stimuli of high activation, from high word frequency and also repetitive presentation in an experiment. A probe target in the control condition, given its high activation, was less influenced by the competition imposed by probe distractors.

If the competition effect in the control condition reflects the degree of interference imposed by distractors, the results show dissociation between interference and negative priming effects. Although measures of response competition and negative priming usually show a positive correlation, as is predicted by both inhibition and retrieval accounts of negative priming (see Fox, 1998, and May, Kane, \& Hasher, 1995, for discussions on the relation), dissociation does exist between interference in the prime trial and negative priming in the probe trial (see May et al., 1995). For example, Fox $(1994,1995)$ found reduced distractor interference when the location of a prime target was precued, and yet the effect of negative priming was not altered by precuing. That is, significant negative priming can be found even when data show no interference effect induced by distractors. Richards (1999) replicated the dissociation induced by precuing. Coloring a single letter of a word eliminated Stroop interference, and yet negative priming remained intact (Marí-Beffa, Estévez, \& Danziger, 2000). In Experiment 4 of Fox's (1998) study, prime distractors not grouped with targets by connecting lines did not produce a response competition effect and yet resulted in a marginally significant positive priming effect in probe trials. Similarly, object-based grouping influenced negative priming (Fox, 1998; Fuentes et al., 1998) and yet failed to produce interference in certain experimental contexts (Shomstein \& Yantis, 2002).

The experimental context also influences the impact of distractors on the selection process. Only a small set of stimuli was used in this study. According to Strayer and his colleagues (Malley \& Strayer, 1995; Strayer \& Grison, 1999), stimuli that have been repeated many times in an experimental session are in a state of high competition. Thus, the distractors in the low-competition condition of this study should also have competed strongly, because we used a small set of eight Chinese character words. Yet no negative priming was observed in this condition. Tipper et al. (2002) have emphasized the notion of relative salience in accounting for different findings under identical conditions that are embedded in different experimental contexts. We agree and suggest that relative salience may have produced the null effect of negative priming in the low-competition condition.
Tipper et al. (2002) indicated that competition from distractors is not absolute. The psychological magnitude of competition is determined by the intensity of the stimulus itself, relative to the intensity of other stimuli. Thus, the level of competition from the same stimulus may vary as the context alters. In this study, high-and low-competition trials were randomly mixed in an experimental session. As compared with the higher level of competition in trials with perceptual grouping, the level of competition is relatively low in trials without perceptual grouping. The relative salience differentiates low-competition trials (i.e., target and distractors are not grouped together) from highcompetition trials (i.e., target and distractors are grouped together). Thus, negative priming is observed in the highcompetition condition, and not in the low-competition condition. Distractor competition at probe onset is important.

The importance that distractor competition has in probe trials can explain the finding that the negative priming effect was smaller or was eliminated when interference from probe distractors was low. Kane et al. (1997) found a trend of positive, instead of negative, priming when removing pixels or adding visual noise to perceptually degrade probe distractors. When neither probe targets nor probe distractors were perceptually degraded, a significant negative priming effect was found. It is likely that perceptual degradation can reduce competition from probe distractors, which is important to the manifestation of negative priming.

The importance that distractor competition has in probe trials can also explain the finding that the negative priming effect was larger when interference from probe distractors was high. The results in Stadler and Hogan's (1996) study support the involvement of probe distractors in negative priming. In one condition (IA), equivalent to the conventional IR condition, the prime distractor became the target of the subsequent probe trial (e.g., $d \mathrm{t} \mathrm{d} \rightarrow \mathrm{n} \mathrm{d} \mathrm{n}$ ). They found a significant negative priming effect $(-11 \mathrm{msec})$, in comparison with the control condition. In another condition (AI), the prime target became the distractor of the subsequent probe trial (e.g., dtd $\rightarrow \mathrm{tn} t$ ). Because the probe distractors had been recently attended, they had a high level of activation and, hence, a high level of competition. A significant competition effect was observed ( -8 mesc). In a third condition (IA/AI), the prime distractor became the probe target and the prime target became the probe distractor (e.g., $\mathrm{d} \mathrm{t} \mathrm{d} \rightarrow \mathrm{t} \mathrm{d} \mathrm{t}$ ). They found a larger negative priming effect $(-44 \mathrm{msec})$ in the IA/AI condition. This cost cannot be explained by the summation of the negative priming effect and the competition effect, because it is larger than the sum of these two effects $(-19 \mathrm{msec})$. Instead, this interaction implies that negative priming is larger when probe distractors impose strong competition.

Assuming that probe distractors in the same perceptual group impose strong competition, the influence of distractor competition at probe onset is consistent with Houghton and Tipper's (1994) inhibition account of negative priming. The memory retrieval account (Neill, 1997; Neill \& Joordens, 2002; Neill \& Mathis, 1998; Neill 
et al., 1992) also can account for the results in the highcompetition condition, by proposing that the high competition imposed by the probe distractors lengthened algorithmic computation, so that memory retrieval prevailed in determining task performance. Thus, negative priming manifested in the high-competition condition. The retrieval account, however, needs to explain why negative priming did not manifest in the low-competition condition of Experiment 2. In this low-competition condition, stimulus activation was high, and the perceptual similarity was relatively higher than similarity in the high-competition condition, encouraging memory retrieval. Yet negative priming was not significant.

Negative priming appears to be the result of multiple mechanisms that are dynamically influenced by the experimental context and, hence, the relative salience of different manipulations. In addition to serving as competitors in the selection race at probe onset, characteristics of the probe distractors can influence attentional set (Milliken et al., 1999) and memory retrieval (Neill et al., 1994; Neill \& Valdes, 1992). The role of competition in probe distractors was demonstrated in this study, in which every probe trial consisted of conflicting information. Moreover, the similarity manipulation in Experiment 2 may have been less salient than the manipulation of distractor competition. Thus, the role as a competitorin the selection race at probe onset masks the influence of similarity manipulation.

In an experimental context in which nonconflict trials are randomly mixed with conflict trials during probe trials (Moore, 1994) or in which the probability of nonconflict trials is low at 25\% (Milliken et al., 1999), probe trials without conflicting distractors also show negative priming. That is, competition from probe distractors is not important. The selection state (Moore, 1994; Tipper \& Cranston, 1985) or an attentional set (Milliken et al., 1999) is more important in this context. Negative priming manifests when participants adopt an attentional set to prevent translation of distracting information into a response (Milliken et al., 1999). This attentional set is initiated when nonconflict and conflict trials are randomly mixed with equal frequency or when conflict trials occur more frequently. Perhaps it is more efficient for the human information-processing system to maintain a constant selection state than to turn selection mechanisms on and off. When the majority of the trials do not contain distracting information, the attentional set is not activated, to conserve cognitive resources. Thus, negative priming is eliminated for nonconflict trials when the probability of their occurrence is $75 \%$ (Milliken et al., 1999) or when nonconflict trials are presented in separate blocks (Moore, 1994).

In addition to their role of changing the attentional set or as competitors in the race with the target, probe distractors also can provide contextual cues for operation of the retrieval process. Because the retrieval process plays an important role in negative priming (Neill \& Mathis, 1998; Neill et al., 1994; Neill \& Valdes, 1992; Tipper, 2001), the priming effect should be subject to the influ- ence of variables that affect the retrieval process. Because probe distractors can influence contextual similarity in reference to prime trials, they should influence the retrieval process through the encoding specificity principle (Tulving \& Thomson, 1973). Evidence in support of this role of probe distractors shows that negative priming is influenced by prime-probe similarity. Prime-probe similarity in perceptual configuration, level of competition, or both could have produced the accuracy data in Experiment 2.

In sum, probe distractors play multiple roles in the manifestation of negative priming - as a contextual cue for memory retrieval, as an igniter for attentional set, and as a competitor in the race at probe onset. Negative priming is not simply the result of reactive inhibition as a protection against competition in prime trials. Negative priming, instead, results from the dual flow of information where the past (prime) and the present (probe) interact (Tipper, 2001). The challenge is to uncover the dynamics in the interaction between the past and the present that influence everyday perception and performance.

\section{REFERENCES}

Allport, D. A. (1971). Parallel encoding within and between elementary stimulus dimensions. Perception \& Psychophysics, 10, 104-108. BAYLIS, G. C., \& DRIVER, J. (1992). Visual parsing and response competition: The effect of grouping factors. Perception \& Psychophysics, 51, 145-162.

CHAо, H.-F. (2001). The role of probe distractors in negative priming. Unpublished master's thesis, National Taiwan University, Taipei.

CHAO, H.-F., \& YEH, Y.-Y. (2002). The role of probe distractors in negative priming. Manuscript submitted for publication.

ChiAPPE, D. L., \& MACLEOD, C. M. (1995). Negative priming is not task bound: A consistent pattern across naming and categorization tasks. Psychonomic Bulletin \& Review, 2, 364-369.

Conway, A. R. A., Tuholski, S. W., Shisler, R. J., \& Engle, R. W. (1999). The effect of memory load on negative priming: An individual differences investigation. Memory \& Cognition, 27, 1042-1050.

DAGENBACH, D., \& CARR, T. H. (EDS.) (1994). Inhibitory processes in attention, memory, and language. San Diego: Academic Press.

Davis, G., Driver, J., PAVAni, F., \& She Pherd, A. (2000). Reappraising the apparent costs of attending to two separate visual objects. $\mathrm{Vi}$ sion Research, 40, 1323-1332.

De Sche PPER, B., \& Treisman, A. (1996). Visual memory for novel shapes: Implicit coding without attention. Journal of Experimental Psychology: Learning, Memory, \& Cognition, 22, 27-47.

Donnelly, N., Humphreys, G. W., \& Riddoch, M. J. (1991). Parallel computation of primitive shape descriptions. Journal of Experimental Psychology: Human Perception \& Performance, 17, 561-570.

Driver, J., \& BAYLIS, G. (1989). Movement and visual attention: The spotlight metaphor breaks down. Journal of Experimental Psychology: Human Perception \& Performance, 15, 448-456.

DunCAN, J. (1984). Selective attention and the organization of visual information. Journal of Experimental Psychology: General, 113, 501-517.

DunCAN, J. (1995). Target and nontarget grouping in visual search. Perception \& Psychophysics, 57, 117-120.

DunCAN, J., \& NimMO-Smith, I. (1996). Objects and attributes in divided attention: Surface and boundary systems. Perception \& Psychophysics, 58, 1076-1084.

Engle, R. W., Conway, A. R. A., Tuholski, S. W., \& Shisler, R. J. (1995). A resource account of inhibition. Psychological Science, 6 , 122-125.

ERIKSEN, B. A., \& ERIKSEN, C. W. (1974). Effects of noise letters upon the identification of a target letter in a nonsearch task. Perception \& Psychophysics, 16, 143-149. 
Forster, K. I., \& Forster, J. C. (2003). DMDX: A Windows display program with millisecond accuracy. Behavior Research Methods, Instruments, \& Computers, 35, 116-124.

FoX, E. (1994). Interference and negative priming from ignored distractors: The role of selection difficulty. Perception \& Psychophysics, 56, 565-574.

Fox, E. (1995). Pre-cuing target location reduces interference but not negative priming from visual distractors. Quarterly Journal of Experimental Psychology, 48A, 26-40.

Fox, E. (1998). Perceptual grouping and visual selective attention. Perception \& Psychophysics, 60, 1004-1021.

Fox, E., \& DE FOCKERT, J. W. (1998). Negative priming depends on prime-probe similarity: Evidence for episodic retrieval. Psychonomic Bulletin \& Review, 5, 107-113.

Fuentes, L. J., Humphreys, G. W., Agis, I. F., Carmona, E., \& CATENA, A. (1998). Object-based perceptual grouping affects negative priming. Journal of Experimental Psychology: Human Perception \& Performance, 24, 664-672.

Hasher, L., Zacks, R. T., Stoltzfus, E. R., Kane, M. J., \& Connelly, S. L. (1996). On the time course of negative priming: Another look. Psychonomic Bulletin \& Review, 3, 231-237.

Houghton, G., \& TipPeR, S. P. (1994). A model of inhibitory mechanisms in selective attention. In D. Dagenbach \& T. H. Carr (Eds.), Inhibitory processes in attention, memory, and language (pp. 53-112). San Diego: Academic Press.

Kane, M. J., May, C. P., Hasher, L., Rahhal, T., \& Stoltzfus, E. R. (1997). Dual mechanisms of negative priming. Journal of Experimental Psychology: Human Perception \& Performance, 23, 632-650.

KrAmer, A. F., \& Strayer, D. L. (2001). Influence of stimulus repetition on negative priming. Psychology \& Aging, 16, 580-587.

LAPPIN, J. S. (1967). Attention in the identification of stimuli in complex visual displays. Journal of Experimental Psychology, 75, 321-328.

LowE, D. G. (1979). Strategies, context, and the mechanism of response inhibition. Memory \& Cognition, 7, 382-389.

MacDonald, P. A., Joordens, S., \& SeERgobin, K. N. (1999). Negative priming effects that are bigger than a breadbox: Attending to distractors does not eliminate negative priming, it enhances it. Memory \& Cognition, 27, 197-207.

Malley, G. B., \& StrayeR, D. L. (1995). Effect of stimulus repetition on positive and negative identity priming. Perception \& Psychophysics, 57, 657-667.

Marí-Beffa, P., Est Éve Z, A. F., \& Danziger, S. (2000). Stroop interference and negative priming: Problems with interferences from null results. Psychonomic Bulletin \& Review, 7, 499-503.

May, C. P., Kane, M. J., \& Hasher, L. (1995). Determinants of negative priming. Psychological Bulletin, 118, 35-54.

Milliken, B., Joordens, S., Merikle, P. M., \& Seiffert, A. E. (1998). Selective attention: A reevaluation of the implications of negative priming. Psychological Review, 105, 203-229.

Milliken, B., Lupiáñez, J., Debner, J., \& Abello, B. (1999). Automatic and controlled processing in Stroop negative priming: The role of attentional set. Journal of Experimental Psychology: Learning, Memory, \& Cognition, 25, 1384-1402.

Ministry of EdUCATION COMMITTEE FOR THE PROMOTION AND PROPAGATION OF THE NATIONAL LANGUAGE (1997). The frequency statistics of the words and phrases in the compiled materials of the Concise Mandarin Dictionary. Taipei, Taiwan: Ministry of Education.

Moore, C. M. (1994). Negative priming depends on probe-trial conflict: Where has all the inhibition gone? Perception \& Psychophysics, 56, 133-147.

Moore, C. M. (1996). Does negative priming imply preselective identification of irrelevant stimuli? Psychonomic Bulletin \& Review, 3, 91-94.

NE ILL, W. T. (1977). Inhibitory and facilitatory processes in selective attention. Journal of Experimental Psychology: Human Perception \& Performance, 3, 444-450.

NEILL, W. T. (1997). Episodic retrieval in negative priming and repetition priming. Journal of Experimental Psychology: Learning, Memory, \& Cognition, 23, 1291-1305.

NeILL, W. T., \& JoORdens, S. (2002). Negative priming and multiple repetition: A reply to Grison and Strayer (2001). Perception \& Psychophysics, 64, 855-860.
Neill, W. T., \& Mathis, K. M. (1998). Transfer-inappropriate processing: Negative priming and related phenomena. In D. L. Medin (Ed.), The psychology of learning and motivation: Advances in research and theory (Vol. 38, pp. 1-44). San Diego: Academic Press.

NeILl, W. T., Terry, K. M., \& VAldes, L. A. (1994). Negative priming without probe selection. Psychonomic Bulletin \& Review, 1, 119-121.

NeILL, W. T., \& VALDES, L. A. (1992). Persistence of negative priming: Steady state or decay? Journal of Experimental Psychology: Learning, Memory, \& Cognition, 18, 565-576.

NeILL, W. T., \& VALDES, L. A. (1996). Facilitatory and inhibitory aspects of attention. In A. F. Kramer, M. G. H. Coles, \& G. D. Logan (Eds.), Converging operations in the study of visual selective attention (pp. 77-106). Washington, DC: American Psychological Association. Neill, W. T., Valdes, L. A., Terry, K. M., \& Gorfein, D. S. (1992). Persistence of negative priming: II. Evidence for episodic trace retrieval. Journal of Experimental Psychology: Learning, Memory, \& Cognition, 18, 993-1000.

Neumann, E., \& DeSchepper, B. G. (1991). Costs and benefits of target activation and distractor inhibition in selective attention. Journal of Experimental Psychology: Learning, Memory, \& Cognition, 17, 1136-1145.

PomerantZ, J. R. (1981). Perceptual organization in information processing. In M. Kubovy \& J. R. Pomerantz (Eds.), Perceptual organization (pp. 141-180). Hillsdale, NJ: Erlbaum.

RichardS, A. (1999). The effects of cueing target location and response mode on interference and negative priming using a visual selection paradigm. Quarterly Journal of Experimental Psychology, 52A, 449-463.

Shomstein, S., \& Yantis, S. (2002). Object-based attention: Sensory modulation or priority setting? Perception \& Psychophysics, 64, 41-51.

STAdler, M. A., \& Hogan, M. E. (1996). Varieties of positive and negative priming. Psychonomic Bulletin \& Review, 3, 87-90.

Stolz, J. A., \& Neely, J. H. (2001). Taking a bright view of negative priming in the light of dim stimuli: Further evidence for memory confusion during episodic retrieval. Canadian Journal of Experimental Psychology, 55, 219-230.

Strayer, D. L., Drews, F. A., \& Albert, R. W. (2002). Negative priming and stimulus repetition: A reply to Neill and Joordens (2002).Perception \& Psychophysics, 64, 861-865.

StRAYER, D. L., \& GRISON, S. (1999). Negative identity priming is contingent on stimulus repetition. Journal of Experimental Psychology: Human Perception \& Performance, 25, 24-38.

TIPPER, S. P. (1985). The negative priming effect: Inhibitory priming by ignored objects. Quarterly Journal of Experimental Psychology, 37A, 571-590.

TIPPER, S. P. (2001). Does negative priming reflect inhibitory mechanisms? A review and integration of conflicting views. Quarterly Journal of Experimental Psychology, 54A, 321-343.

Tipper, S. P., Brehaut, J. C., \& Driver, J. (1990). Selection of moving and static objects for the control of spatially directed action. Journal of Experimental Psychology: Human Perception \& Performance, 16, 492-504.

TIPPER, S. P., \& CRANSTON, M. (1985). Selective attention and priming: Inhibitory and facilitatory effects of ignored primes. Quarterly Journal of Experimental Psychology, 37A, 591-611.

TIPPER, S. P., \& DRIVER, J. (1988). Negative priming between pictures and words in a selective attention task: Evidence for semantic processing of ignored stimuli. Memory \& Cognition, 16, 64-70.

Tipper, S. P., Meegan, D., \& Howard, L. A. (2002). Action-centered negative priming: Evidence for reactive inhibition. Visual Cognition, 9, 591-614.

Tipper, S. P., Weaver, B., Cameron, S., Brehaut, J. C., \& Bastedo, J. (1991). Inhibitory mechanisms of attention in identification and localization tasks: Time course and disruption. Journal of Experimental Psychology: Learning, Memory, \& Cognition, 17, 681-692.

Treisman, A. M., \& Gelade, G. (1980). A feature-integration theory of attention. Cognitive Psychology, 12, 97-136.

Treisman, A. [M.], Kahneman, D., \& Burkell, J. (1983). Perceptual objects and the cost of filtering. Perception \& Psychophysics, 33, 527-532.

Tulving, E., \& ThOMson, D. M. (1973). Encoding specificity and retrieval processes in episodic memory. Psychological Review, 80, 352373. 
WheEler, M. E., \& Treisman, A. M. (2002). Binding in short-term visual memory. Journal of Experimental Psychology: General, 131, 48-64.

Wing, A., \& ALLPORT, D. A. (1972). Multidimensional encoding of visual form. Perception \& Psychophysics, 12, 474-476.

WoNG, K. F. E. (2000). Dissociative prime-probe contextual similarity effects on negative priming and repetition priming: A challenge to episodic retrieval as a unified account of negative priming. Journal of Experimental Psychology: Learning, Memory, \& Cognition, 26, 1411-1422.

XU, Y. (2002). Limitations of object-based feature encoding in visual short-term memory. Journal of Experimental Psychology: Human Perception \& Performance, 28, 458-468.

YEE, P. L. (1991). Semantic inhibition of ignored words during a figure classification task. Quarterly Journal of Experimental Psychology, 43A, 127-153.

\section{NOTES}

1. We thank Paloma Marí-Beffa for suggesting this experiment.

2. We asked 8 undergraduate students of National Taiwan University, who had not participated in this series of experiments, to judge whether the prime display was similar to the high-competition probe display or the low-competition probe display. The order in which these two probe displays were presented was counterbalanced. All the participants indicated that the prime display was similar to the low-competition probe display.

(Manuscript received October 8, 2002, revision accepted for publication June 25, 2003.) 